\title{
Picea mariana Leaf Oil
}

National Cancer Institute

\section{Source}

National Cancer Institute. Picea mariana Leaf Oil. NCI Thesaurus. Code C74285.

The essential oil extracted from the needles and twigs of the black spruce, Picea

mariana. Picea mariana leaf oil is used for its aromatic properties in soaps and skincare products. 